\title{
ON LANGUAGE LEARNER ATTITUDES AND ACHIEVEMENT, AND THEIR RELATION WITH MOTIVATION
}

\author{
JERZY ZYBERT
}

Attitudes are considered to have a strong impact on foreign language learners' achievement which apparently results from their motivation. The conviction that these factors are interrelated and interdependent is supported by research and observation.

The concept of attitude is commonly referred to as a subjective appraisal of an object $^{1}$.

Attitude is symptomatically expressed through people's emotional, cognitive, and behavioural reactions which, nevertheless, do not necessarily need to occur together. The reactions themselves are considered to be actual manifestations of an individual's positive or negative orientation or a subjective inclination to assess an object as worth pursuing. In consequence, attitudes can be described in terms of the features that characterize them, for example, such as the following:

1. Attitudes are cognitive (i.e., are capable of being thought about) and affective (i.e., have feelings and emotions attached to them)

2. Attitudes are dimensional rather than bipolar - they vary in degree of favourability / unfavourability

3. Attitudes predispose a person to act in a certain way, but the relationship between attitudes and actions is not essentially strong

4. Attitudes are learnt, not inherited or generally endowed

5. Attitudes tend to persist but can be modified by experience

\footnotetext{
${ }^{1}$ In psychology, an object is an entity such as a phenomenon, question, idea, action, value, etc.
} 
With regard to foreign language (FL) learning, the most common attitudes one can distinguish among students are the attitudes toward the target language itself, its native speakers, their position in contemporary world, etc. In that regard attitude can be defined as the learners' general stance concerning whatever is involved in the language learning process. More specifically, it relates to learners' stereotypical opinions, beliefs, convictions, or perceptions adopted before or developed during language learning; it may include views on the foreign language such as, e.g., that it is difficult or easy to learn, is pretty or unattractive (sounds beautiful [pleasing, agreeable] or unpleasant [harsh]), is useful or useless in everyday/professional life, etc. Moreover, various other attitudes can be held by learners toward native speakers (their culture, heritage, etc.), the teacher, peers in the classroom, or even parents (whether they approve FL learning and support it or not). As is seen learners' attitudes can be numerous and multifarious. However, it seems obvious that it is only positive attitudes that determine success since they make the language being learnt attractive to students and worth investing the effort to learn it. Positive attitudes will compensate for unfavourable learning environment including poor teachers or learning/teaching materials, parents' disinterest (no support), and even classmates' ridicule (a good language learner may be treated as a swot). Moreover, it appears that the more instances of positive attitude are involved the higher the learner's achievement. Apparently, this circumstance has an important impact on attitudes; hence, of interest should be the degree to which particular attitudes exert influence and determine students' achievement, which actually results from their being attracted to the language. Additionally, it can safely be assumed that attitude is strongly related to motivation, if not synonymous with it, which is commonly believed to be the strongest factor that determines achievement.

As was mentioned students often hold diverse beliefs about the phenomena and problems pertaining to foreign languages; they also relate their beliefs to language learning. Furthermore, with regard to the variety of attitudes they can also be considered in terms of beliefs. For example, according to Richards and Lockhart (2001: 52-58) students have beliefs about:

- the nature of English

- speakers of English

- the four basic language skills

- teaching

- language learning

- appropriate classroom behaviour

- self

- goals

Researchers are convinced that such beliefs "play a central role in learning experience and achievement" (Cotterral, 1999: 494). Hence, this has aroused interest in finding evidence for this apparent link. For example, an instrument to assess stu- 
dents' beliefs concerning language learning was developed for this purpose (Beliefs about language learning inventory, Horwitz, 1987).

Beliefs, whether they are emotionally biased or neutral, justified or illusive, underlie students' attitudes and decide their overall involvement in learning; they simultaneously shape their attitudes and determine their intensity. It is also generally considered that attitudes develop on the basis of learners' prior educational experience. For example, apart from Richards and Lockhart's list of beliefs cited above, experience has a strong effect on their approaches to the materials and methods or techniques employed in the classroom, on the relations with the teacher, the perception of him/her and of his/her teaching style and, most of all, toward the native speakers and the culture that they represent, etc. Such aspects of experience can be compared to what Allwright and Bailey (1991) have called receptivity, i.e. learners' openness (or its lack) to the target language and to whatever is related to learning it. It follows that attitude is the learner's cognitive/affective predisposition that entails his evaluation of his own preferences on the one hand, and of his emotional predisposition that exhibits his likes or dislikes on the other. All this will inevitably exert a weighty effect on students' engagement in performing language learning tasks and on the effectiveness of the language instruction that they are exposed to and are expected to learn from. Moreover, according to Benson (2001), beliefs are factors that, among others, describe the conditions that are dependent on context or experience $^{2}$; it follows that they are amenable to change. For example, Little and Singleton (1990) have found that students' attitudes are affected by their earlier experience in education and, especially, in learning foreign languages. Thus, it can be assumed that attitudes change as a function of experience, whether it is mental or emotional.

It seems appropriate to remark that other views are also held; for example, Baker (1988) claims that the relationship between attitudes and actions is not strong. This disparity may seem rather strange in the light of the apparent ambition and desire of most students, who admit that they do wish to develop foreign language skills - after all, these emotions determine that attitudes are necessarily positive and thus enhance learning. Yet, teaching practice and teachers' observation confirm that such a situation is often the case, particularly among beginners - their attitude that is naturally linked to initial motivation and interest in language which is caused by novelty does not translate directly into students' involvement in performing communicative language tasks. This can be attributed to their personality traits (anxiety, low risk-taking, introversion, etc.) on the one hand, and to their learning inexperience, or rather, to their lack of learning autonomy, on the other. It is worth recalling Oxford's (1999: 111) definition, according to which, autonomy is:

\footnotetext{
${ }^{2}$ Experience encompasses knowledge of something or of some past event or skill in something gained/developed through exposure to that thing or event or participation in it.
} 
ability and willingness to perform a language task without assistance with adaptability to the situational

demands, with transferability to other relevant contexts, and with reflection, accompanied by relevant

action (the use, usually conscious and intentional, of appropriate learning strategies) reflecting both

ability and willingness.

In discussing FL language students' beliefs, it is important to observe that they often realize they have strengths and weaknesses. Consequently, a disbelief in one's potential definitely hinders learning, e.g. if your self-esteem or learning autonomy is low, or you believe you are too old to start learning a foreign language, you will not succeed. Serious difficulties in FL learning are caused, among others, by negative attitudes. Beliefs about the nature of language learning refer to its overall complexity and typological distance. They also refer to the perception of the language in aesthetic terms. On the other hand, the so-called good language learners use a substantial number of strategies spontaneously (cf. Zybert, 2010). They perceive the learning value of applying strategies to solving learning and communication problems. It is their prior experience that makes them choose strategies which are most suitable for given tasks. These learners also believe that it is worth investing effort in being trained in strategy use.

Together with the accepted assumption that attitudes have a serious impact on achievement, it is also believed that success is most strongly determined by motivation, which apparently is related to the link between learning experience and achievement. In fact, while discussing the role of motivation (or its lack) in foreign language learning, researchers almost always connect (if not integrate) it concurrently with attitudes. For example, Gardner (1985: 120) claims that "positive attitudes and motivation are related to success in second language learning". This stance is supported, e.g., by Brown (2000: 181) according to whom, "It seems clear that second language learners benefit from positive attitudes and that negative attitudes may lead to decreased motivation and ... unsuccessful attainment of proficiency". Attitudes are therefore customarily considered to be important determinants of ultimate attainment. Moreover, attitudes are frequently linked with motivation to the extent that many researchers claim that they are inseparable and combine (or completely overlap) rather than supplement each other (c.f., Skehan, 1989). There certainly exists feedback on motivation from attitude: generally, positive attitudes strengthen motivation and those who experience learning success have their attitudes reinforced; conversely, motivation deteriorates due to negative attitudes which become reinforced with perceived failure.

The association between motivation and attitude is also recognized by psychologists researching individual learner differences: in fact, the instruments they use to measure the influence of these differences on achievement normally include both. 
For example, Gardner (1985) has constructed the Attitude and Motivation Test Battery (AMBT) which manifestly emphasizes the inseparability of the two variables. Since tests of this kind contain questions about the test-takers' attitudes toward the foreign language, its native speakers, family encouragement, etc., attitude can, once again, be regarded as an aspect or a component of motivation.

The close connection between attitudes and motivation has actually been documented empirically. For example, it has been shown that language learning is significantly affected by reciprocal attitudes of various individuals involved in a learning situation; these include the learner, the teacher, peers, parents, native speakers of the target language, etc. (cf. Spolsky, 1969: 237). It should thus be logically assumed that achievement strongly depends on learner-favourable attitudes and that it largely stems from the feedback that learners receive from significant others.

As already mentioned above, motivation to learn a foreign language also depends to a large extent on the students' positive stance or predisposition towards the target language community (i.e., the reference group), their culture, history, attainments, etc., which undoubtedly fosters their motivation. On the other hand, with a negative orientation, e.g., if a learner bears some kind of prejudice or animosity toward the target language native speakers, his bias will influence learning their language negatively and, certainly, will not induce motivation of the integrative kind. A negative attitude may develop from an erroneous conviction that a given foreign language is very difficult to master, that it is of little practical use for the learner or that it is not worth the time and effort that he has to invest in learning it this will not cause instrumental motivation either.

To state that disapproving attitudes are undesired is an obvious platitude. Thus preventing them is a clear obligation of every teacher:

Negative attitudes usually emerge either from false stereotyping or from undue ethnocentrism. (...). Teachers can aid students in dispelling what are often myths about other cultures, and replace those myths with a realistic understanding of the other culture as one that is different from one's own, yet to be respected and valued. (Brown, 1987: 127)

The claim concerning the dependence of motivation on attitudes has been supported by research. Findings have demonstrated that those language learners who have not developed positive attitudes are little motivated, if at all; they are complete opposites of the students who have overall positive attitudes. Successful learners' motivation results from their affirmative view of the target language, of the teacher, etc., and from their desire to satisfy their own interest in the foreign culture and the target language community. Consequently, the former type of learner actually provides the teacher with splendid opportunity to demonstrate his/her vocational skills in actual teaching practice: a good teacher is able to persuade his/her pupils to adopt his/her own attitudes - instilling constructive viewpoints in reluctant students will, simultaneously, instigate motivation in them. Clearly, a positive attitude towards the 
target language will generate an emotional involvement in the mental process of learning it. This gives the student a basis for the rational conviction that his effort is not futile, regardless of the learning situation, the teaching materials and method, the teacher, etc. On the contrary, a negative attitude allows predicting that the learner is going to have a difficult time.

All in all, attitude is in reality a sort of compelling and indispensable ingredient of or, at least, a supplement to motivation; therefore these two constructs should be considered in tandem rather than separately. In consequence, attitudes are fervently recommended to be taken into account in classroom teaching (cf. Bialystok, 1978; Naiman et al., 1978). For example, it is argued that attitudes tie with self-esteem, since positive beliefs about one's own potential with regard to language learning, especially about learning its particular aspects, facilitate language learning processes. It follows that attitudes stimulate the learner to approach learning tasks rationally with no fear or bias when he considers it feasible. This actually raises his selfesteem, which in turn strengthens his motivation and learning autonomy and, overall, fosters a willingness to learn. It also shows that language learning processes are complex indeed as they involve a number of interrelated factors and indicates that they underlie learners' individual contributions to learning requiring his autonomous approach to language learning. Such a picture of a language learner stands in contrast to the traditional image of a learner. According to the latter, he is totally dependent on the teacher, who has full control over his learning processes. Such a picture contradicts actual facts: it often happens that learners are able to perform what they have not been taught in the classroom (a phenomenon that some teachers are not able to conceive of).

There are a number of factors that intrinsically tie with attitudes and have an effect on their modification: the most evident of these are learners' age and experience. For example, it is generally known that children are entirely open to accept cultural differences before the age of ten, whereas on entering their teens they are inclined to reject whatever is different: they consider it then as alien and by and large "bad"3 (Gardner and Lambert, 1972). To a little child it is parents and elder siblings' opinions, convictions, suggestions, and prompting that are regarded by him as ultimate values to be followed. This perspective usually continues through school years. However, the impact of caregivers' influence gradually diminishes as learners get older. In the lower grades it is the teachers who are admired by young learners; it is commonly known that their diligence very often results from their fondness of the teacher - students try to do their best just because they wish to obtain her appreciation and praise; therefore they also devote much attention to the subject taught by their favourite teacher. Conversely, learners dislike the subject taught by the teacher whom they dislike. In this situation one must not undervalue the emotional relations

\footnotetext{
${ }^{3}$ N.B. This argument is used in support of an early start in FL learning.
} 
of students with their teacher. Yet, the teacher becomes definitely less significant to students when they reach adolescence. At this stage of their emotional development they typically rebel against established authorities, tend to become independent of them, and try to be autonomous in their judgement and opinion. This is the time when peers become the most significant partners of one another and, consequently, their attitudes become underlain by emotions then. It is peers that become authorities - their attitudes are especially easily adopted by weaker classmates. This results in a serious qualitative change of their attitudes. Still, it is generally recognized that a teacher's wisdom and tactful dealing with students win him/her students' respect and, in consequence, will incline them to adopt his/her own attitudes.

The considerations and arguments discussed above purport to the assertion that attitudes are learnt - it is obvious that no-one is born with them. Attitudes, similarly to stereotypes, develop in time and are often shaped by and through interpersonal relations. They are most frequently adopted under the influence of others who hold established general views about various phenomena or objects. Undoubtedly, it is the family, peers, friends and also respected teachers who play the most significant part in shaping early attitudes.

Consequently, attitudes are not immune to change - they can be modified even if they do tend to persist. Earlier assumptions that they are stable have been challenged since relevant research provided evidence to the contrary. They change with time, especially when learning contexts vary (cf. Tanaka and Ellis, 2003). Learner belief systems are now perceived to be dynamic in nature (cf. Hosenfeld, 2003), especially that learners become logically more and more knowledgeable in the course of time.

It is worth noting that in the case of young beginners most of them have little understanding (if any) of what they embark on or of what they can expect in the formal learning situation, i.e., in the language classroom. Their initial interest in L2 is apparently driven mainly by curiosity (in accordance with Maslow's postulate that the "need for exploration" is instinctive). However, when they gradually acquire some general knowledge and gain individual experience they develop subjective views, opinions, and develop impressions which sooner or later shape their attitudes. Consequently, if attitudes are positive, they will attract students to the language itself and enhance their willingness to learn it, thus making them participate in classroom activities. Conversely, an indifferent attitude toward the foreign language will not lead to developing communicative skills - the language knowledge that the learner may obtain then will only be of the declarative kind which is comparable to the knowledge of school subjects and, actually, useless for spontaneous language use.

It needs to be added that arousing and sustaining positive attitudes and motivation for language learning is highly possible, if teachers combine it with teaching culture. This claim is based on the conviction that learners' positive attitudes may stem just from their understanding of the differences and peculiarities of the target culture as it naturally fosters their receptivity, makes learning attractive, and incites 
curiosity and stimulates overall constructive attitudes. In consequence, familiarity with culture strengthens motivation and arms learners with the belief that the goals they pursue are accessible for them, the more that the results they notice give them the feeling that the pursuit itself is not that effortful at all. This, in turn, promotes the development of learners' intercultural communicative competence which, actually, embraces their attitudes, knowledge, and action-oriented skills. With regard to this, Byram (2003) considers attitudes crucial as they affect intercultural curiosity and make learners more open minded. Greene (2003) adds that of equal importance for successful communication is also the knowledge of the mechanisms of social contact that the native and target cultures enter into. It is worth noting that interaction involves more non-verbal than verbal communication: research findings show that only $7 \%$ of messages are conveyed by words, compared to $38 \%$ conveyed by the tone of voice, and as much as 55\% by non-verbal behaviour (Mehrabian, 2009). With regard to skills, a competent communicator is expected to successfully interpret foreign culture events and relate them to his native ones (cf. Byram, 2003). On top of this it is a motivation that is seen as a key quality of communicative competence - according to Greene (2003) - it is activated when one feels a need for communicating with the aim of achieving established goals.

Attitudes may both be formed and/or undergo modifications on the basis of individual experience. Students' unconstructive attitudes to the target language can develop from their unfavourable perception of its native speakers - such attitudes can stem from students' direct unpleasant encounters or contacts with them and from their critical assessment of them. For example, if a student sees a native TL speaker sitting in a restaurant with a cap on and eating with his fingers instead of using cutlery, then such norms of behaviour may not be acceptable for the student; in consequence, a scornful attitude towards the speaker and, in consequence, to his L1 seems inevitable. Lightbown and Spada's (1993: 40) relevant remark captures the point: "Depending on the learner's attitudes, learning a second language can be a source of enrichment or resentment" (emphasis mine). Also indirect experience can develop negative attitudes; for example, behaviours such as resting one's feet on the desk when sitting at one, speaking to others (especially to ladies or superiors) with hands in one's trouser pockets, or chewing gum at official meetings are absolutely unacceptable in European culture. Generally, such scenes (and many others), as displayed in numerous American films, predispose European learners of English negatively against its native speakers and, in consequence, towards learning their language. However, it must be admitted that similar experience may induce positive attitudes, too. For instance, a young man may be impressed by the rough behaviour of the actor he admires and wish to imitate him (tough guy, macho!), which includes learning his language. Since language is an integral part of culture, the learner's attitude toward the native speakers of that language will necessarily and inevitably affect his emotional involvement in learning it in general and its particular aspects (e.g., pronunciation). 
The above considerations allow concluding that attitudes are also driven by emotions. Language teachers can do a lot about modifying students' undesirable and inappropriate attitudes - they are actually expected to influence their students in changing them. It is clear then that teachers must contradict stereotypical perceptions and beliefs held by students; their consistent and systematic struggling against their false views will, hopefully, result in students' abandoning those perceptions and beliefs or at least in lowering their extent or intensity.

From the pedagogical point of view, it is fortunate indeed that attitudes are subject to change - this means that they can be steerable. In consequence, it needs to be emphasized that attitudes should be viewed in dynamic terms. This view suggests that the concept of attitude needs to be treated somewhat differently from that traditionally offered by social psychology, according to which "attitudes refer to general and rather stable orientation towards an object" (Eysenck, 1998: 341; emphasis mine).

As already noted above, teachers can contribute greatly to forming young learners' attitudes when they take into consideration their traits such as, for example, their love for enjoyment and fun. Teachers can easily provide fun, introducing attractive physical activities that are involving and enjoyable for students. The pleasure that young learners derive from such activities undoubtedly creates positive attitudes toward the target language which they will associate with the joy they experience while playing and speaking it; simultaneously, their desire for more tasks of the kind not only triggers more language practice but also provides more exposure to input (cf. Moon, 2000). Moreover, with regard to the flow theory (Csikszentmihalyi, 1990), students' going through this kind of experience should also enhance their motivation for further language learning. All this is extremely important and should definitely be considered by teachers in their relationship with students, particularly in the attempts to motivate them and to form positive attitudes to language learning.

Good teachers will form positive attitudes if their students find them trustworthy and credible. Thus establishing a friendly relationship with students is of paramount importance for the efficacy of the teacher's emotional appeals; these can be regarded as attempts to change negative attitudes or evoke positive ones. Teachers cannot be perceived as censors of students' performance or critics of their achievements; they should rather be perceived as advisors who help them develop feelings of selfefficacy and empower them to challenge various situations (Bandura, 1992).

\section{References}

Allwright, D. and K. Bailey. 1991. Focus on the language classroom. Cambridge: Cambridge University Press.

Bandura, A. 1992. "Self-efficacy mechanism in human agency". American Psychologist 37. 122-147.

Benson, P. 2001. Teaching and researching autonomy in language learning. Harlow: Longman. 
Bialystok, E. 1978. "A theoretical model of second language learning”. Language Learning 28. 69-83.

Brown, H.D. 1987. Principles of language learning and teaching. 2nd ed. Englewood Cliffs, N.J.: Prentice Hall Regents.

Brown, H.D. 2000. Principles of language learning and teaching. London: Longman.

Byram, M. 2003. "Foreign language education in context". In: Bourne, J. and E. Reid (eds). World yearbook of education: language education. London: Kogan Page.

Cotterral, S. 1999. "Key variables in language learning: What do learners believe about them?". System 27.4. 213-238.

Csikszentmihalyi, M. 1990. Flow - the psychology of optimal experience. New York: Harper and Row.

Dörnyei, Z. (ed.). 2003. Attitudes, orientations, and motivations in language learning.Malden: Blackwell Publishing.

Gardner, R.C. 1985. Social psychology and second language learning: The role of attitudes and motivation. London: Edward Arnold.

Gardner, H. and W. Lambert. 1972. Attitudes and motivation in second language learning. Rowley, Mass.: Newbury House.

Greene, J. 2003. "Models of adult communication skills acquisition. Practice and the course of performance improvement". In: Greene, J. and B. Burleson (eds). Handbook of communication and social interaction skills. New York: Psychology Press. 51-92.

Horwitz, E. 1987. "Surveying students' beliefs about language learning". In: Wenden, A. and Rubin, J. (eds.). Learner strategies is language learning. Englewood Cliffs, N.J.: Prentice Hall. 119-129.

Hosenfeld, C. 2003. "Evidence of emergent beliefs of a second language learner: A diary study". In: Kalaja, P. and A. Barcelos (eds.). Beliefs about SLA: new research approaches. Dordrecht: Kluwer Academic Publishers.

Larsen-Freeman, D. and J. Long. 1991. An introduction to second language acquisition research. London: Longman.

Lightbown, P. and N. Spada. 1999. How languages are learnt. Oxford: Oxford University Press.

Little, J. and D. Singleton. 1990. "Cognitive style and learning approach". In: Duda, R. and P. Riley (eds). Learning styles. Nancy: Presses Universitaires de Nancy. 11-19.

Mehrabian, A. 2009. Silent messages. Belmont: Wadsworth.

Moon, J. 2000. Children learning English. Oxford: Macmillan Heinemann.

Oxford, R.L. 1990. Language learning strategies: what every teacher should know. Rowley, Mass.: Newbury House.

Richards, J. and C. Lockhart. 2001. Reflective teaching in second language classrooms. Cambridge: Cambridge University Press.

Skehan, P. 1989. Individual differences in second-language learning. London: Edward Arnold.

Spolsky, B. 1965. "Attitudinal aspects of second language learning”. Language Learning 19. 271-285.

Zybert, J. 2010. "Spontaneous use of vocabulary learning strategies". Studia Anglica Posnaniensia 46.1. 95-107. 